\title{
Factors affecting adoption of pressurized irrigation technology among olive farmers in Northern Iran
}

\author{
Nima Nejadrezaei ${ }^{1} \cdot$ Mohammad Sadegh Allahyari $^{2} \oplus \cdot$ Mina Sadeghzadeh $^{3} \cdot$ Anastasios Michailidis $^{4}$. \\ Hamid El Bilali ${ }^{5}$
}

Received: 7 September 2017 / Accepted: 12 September 2018 / Published online: 4 October 2018

(c) The Author(s) 2018

\begin{abstract}
The main aim of this paper was to investigate factors affecting the adoption of pressurized irrigation technology among Roudbar County olive farmers by path-structural modeling and Unified Theory of Acceptance and Use of Technology. Data were collected through an information technology questionnaire addressing a cross section of 210 managers of olive farms (4.18\% of the statistical population) in the Roudbar County, Northern Iran. Validity of the questionnaire was proofed using several tests (content, face, convergent and discriminant). Likewise, reliability of the questionnaire was tested employing principal component analysis, Cronbach's alpha, Dillon-Goldstein's $\int$ and reagent stability. Descriptive and inferential statistical analysis of the data was accomplished using SPSS $_{\mathrm{V} 19}$ and SmartPLS $_{\mathrm{V} 3}$ software. For testing hypotheses, structural equation model and partial least squares that focus on reagent variance were used. Results show a significant relationship between: (a) performance expectancy and behavioral intention, (b) social influence and behavioral intention, (c) facilitating conditions and use behavior. A significant relationship was also observed between intention to use and use behavior of pressurized irrigation technology. The employed model explains $72 \%$ of behavioral intention variance and $42 \%$ of use behavior of pressurized irrigation technology variance among olive farmers. To increase willingness to accept technology among Roudbar County olive farmers, it is suggested to hold extension and education courses by organizations for raising knowledge and awareness of pressurized irrigation technology. Also, olive farmers can be provided with financial resources and knowledge to enable them to adopt this new irrigation technology.
\end{abstract}

Keywords Pressurized irrigation $\cdot$ Technology adoption $\cdot$ UTAUT model $\cdot$ PLS

Mohammad Sadegh Allahyari

allahyari@iaurasht.ac.ir

1 Faculty of Agronomy and Agro-industry, Polytechnical Institute of Earth and Life Sciences Unilasalle, Rouen, France

2 Department of Agricultural Management, Rasht Branch, Islamic Azad University, Rasht, Iran

3 Young Researchers and Elite Club, Rasht Branch, Islamic Azad University, Rasht, Iran

4 Laboratory of Agricultural Extension and Rural Sociology, Department of Agricultural Economics, Faculty of Agriculture, School of Agriculture, Forestry and Environmental Sciences, Aristotle University of Thessaloniki, Thessaloníki, Greece

5 Centre for Development Research, University of Natural Resources and Life Sciences (BOKU), Vienna, Austria

\section{Introduction}

There are persuasive arguments in favor of growing olive trees and producing the related products all over the world. The main causes of this popularity do not only route in agronomic and economic reasons. However, the environment and human health are some of the most important reasons needed to be considered. This tree is considerably tolerant to drought, and it is capable to be grown in soils which suffer from poor quality and are shallow. These features put this species among the most interesting ones or cultivation in both arid and semiarid areas (Fernandez and Moreno 1999).

In Iran, and especially in Roudbar County, agriculture plays a vital role in socioeconomic development. It is obvious that improvement in agriculture is highly dependent on water. The county of Roudbar enjoys from a Mediterranean climate. In such climate, agriculture is the main and most important consumer of water and a considerable 
percentage of available water resources as well above $80 \%$ is allocated to irrigation (Laraus 2004). Celano et al. (1999) believe that olive trees are efficiently respondent to irrigation management plans.

Due to the fact that there are increasing demand, limited resources, water table variation in space and time, as well as soil contamination, it is required to manage available water resources at farm level optimally (Kumar and Singh 2003). A very important element in successful operation and management of irrigation schemes is efficient water management. It means by irrigation water management is determining when to irrigate, the amount of water to use at each irrigation stage and during each stage of plant, also operating and maintaining the irrigation system. The main purpose of management system is to manage the production system for profit without compromising the environment so that the management is also in agreement with water availability plans. A major concern in management programs is to identify when and how much water to apply or irrigation scheduling on the other words. In this regard, the irrigation method and other field characteristics must be considered carefully (Holzapfel et al. 2009). Since there has been a considerable decrease in olive production in the region over the last decade and traditional irrigation methods in olive groves, it is vitally crucial to study pressurized irrigation technology adoption among olive farmers in Roudbar County.

The importance of this matter is not just confined to this study area, and many studies have been accepted in this regard in Iran and elsewhere in the world in the past decades. Movahedi et al. (2017) in their study that was focused on investigating factors affecting farmers' adoption of pressurized irrigation technology in Asadabad County found that the variables including "perceived usefulness", "perceived ease of use" and "attitude to use" had a significant and positive impact on the decision to accept the use of pressurized irrigation systems. Also, Afrakhteh et al. (2014) in their study that was about analysis of factors affecting adoption and application of sprinkler irrigation by farmers in Famenin County concluded that adoption of sprinkler irrigation systems to be influenced by environmental factors, such as the area under cultivation, access to water, water quality, and non-environmental factors, such as the workforce number in the family, employment diversity and participation in extension education and courses on agricultural water management. Adeoti (2009) study results on factors influencing irrigation technology adoption and its impact on household poverty in Ghana demonstrated that availability of labor and increases in number of extension visits per year are factors that increase the probability of adoption.

The main aim of this descriptive correlational study was to investigate effective factors on adopting technologies among olive farmers in Roudbar County, Northern Iran, by partial least squares (PLS) approach, employing Unified Theory of Acceptance and Use of Technology (UTAUT).

Technology acceptance models try to explain the degree of acceptance of the use of technologies. These theories assess whether the user will be able to accept the new technologies and user's ability to deal with it. Technology acceptance models help managers and decision-makers to assess the success of the introduction of technology to the organization, and motivate users to accept the systems. Unified Theory of Acceptance and Use of Technology (UTAUT) is a user acceptance model that is created by Venkatesh et al. (2003). UTAUT is one of the new models in the field of technology acceptance model, and its purpose is basically to explain user's intention to use technology and to examine usage behavior (Taiwo and Downe 2013). The Unified Theory of Acceptance and Use of Technology integrates constructs across the eight models. The eight models include the Technology Acceptance Model (TAM) (Davis 1989), the Theory of Reasoned Action (TRA) (Fishbein and Ajzen 1975), the Theory of Planned Behavior (TPB) (Ajzen 1991), the Combined TAM and TPB (Taylor and Todd 1995), the Innovation Diffusion Theory (IDT) (Moore and Benbasat 1991; Rogers 2003), the Social Cognitive Theory (SCT) (Bandura 1989; Compeau and Higgins 1995), the Motivational Model (MM) (Davis and Warshaw 1992) and the Model of PC Utilization (MPCU) (Thompson et al. 1991). The UTAUT contains four core determinants of technology use behavior and up to four moderators of key relationships. The UTAUT suggests that performance expectancy, effort expectancy, social influence and facilitating conditions are determinants of behavioral intention or use behavior; and that gender, age, experience and voluntariness of use have moderating effects in the acceptance of technology (Fig. 1).

The results in similar studies on Unified Theory of Acceptance and Use of Technology (UTAUT) show a significant association between performance expectancy and behavior intention (Nejadrezaei et al. 2015; Addo 2014; Yu 2012; Wu et al. 2011; Im et al. 2011; Wang and Shin 2009). In addition, there was a significant relationship between effort expectancy and behavior intention (Im et al. 2011; Wang and Shin 2009). It was also observed that there exists a significant association between social influence and behavior intention (Yu 2012; Wu et al. 2011; Im et al. 2011; Wang and Shin 2009). Finally, a strong association between facilitating condition and use behavior has been proved (Addo 2014; Yu 2012; Im et al. 2011; Wang and Shin 2009). To consider moderating effects, gender is a significant factor which moderated the effects of performance expectancy on behavioral intention (Yu 2012; Wang and Shin 2009); also, social influence has the same effect on behavior intention (Wang and Shin 2009) and the age as well had a considerable moderating effect on effort expectancy on behavior intention (Yu 2012; Wang and Shin 2009). The same trend is 


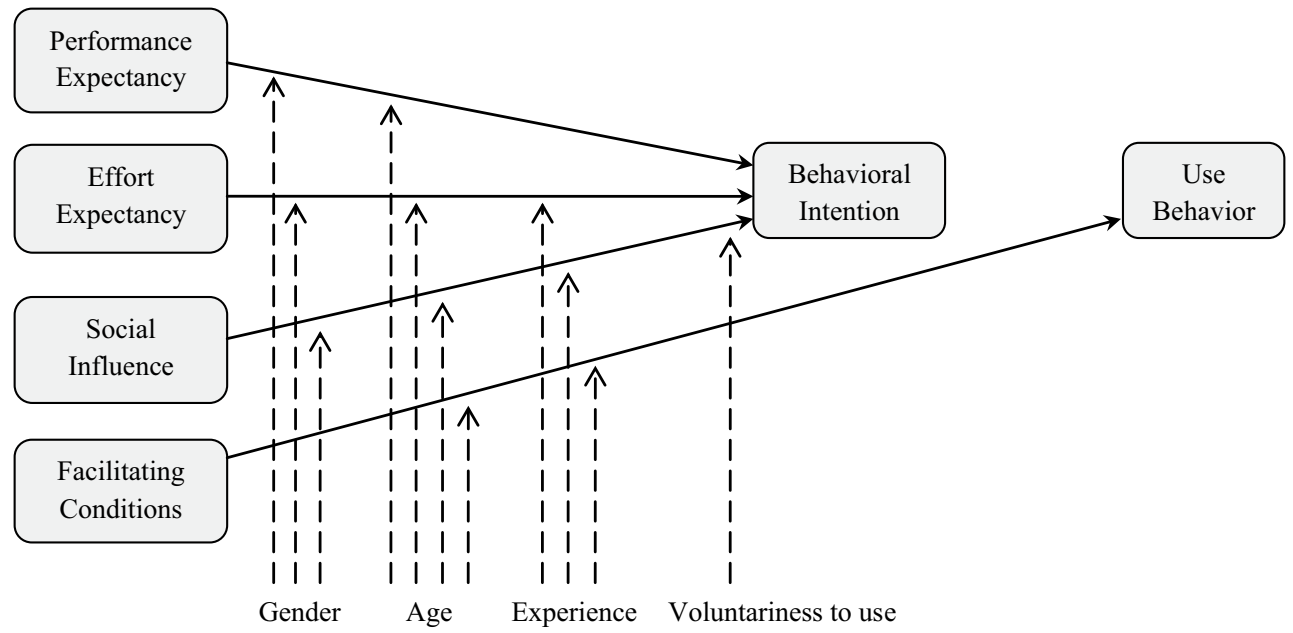

Fig. 1 Theoretical framework of UTAUT (Venkatesh et al. 2003)

observed in the effect of social influence on behavior intention (Yu 2012) and facilitating conditions on actual adoption behavior (Yu 2012).

The paper is organized as follows. In "Research methodology," we describe the methodological framework including the description of the study area, the data collection and the employed econometric models. In "Results," we present the summary statistics, the econometric modeling and the results. Finally, "Discussion and conclusion" concludes.

\section{Research methodology}

This study was carried out by survey design. Study area was Roudbar region of Guilan Province near Caspian Sea in Northern Iran (Fig. 2). This province is one of the main agricultural centers in Iran (Nikkhah et al. 2016; Firouzi et al. 2018).
On the basis of eight prominent models in the research area of technology acceptance, Venkatesh et al. (2003) conducted an empirical study to compare eight competing models and accordingly proposed a unified model.

Statistical population of this research comprises all 5017 olive growers of Roudbar County, while sample size consists of 209 respondents (Bartlett et al. 2001). To achieve the minimum required sample size in this study, a sample of 240 people was considered. Finally, 210 questionnaires were returned from 240 questionnaires distributed (questionnaire return rate was $87.5 \%$ ).

The main study tool was a specific questionnaire based on Venkatesh et al. (2003) information technology issues with six items. In order to test general validity of the questionnaire, content, face, convergent and discriminant validity tests were performed. In addition, in order to test reliability of the questionnaire, principal component analysis and reliability analysis (Cronbach's alpha, Dillon-Goldstein's $\int$ and reagent stability) were used. To accomplish analysis of data,

Fig. 2 Site of study

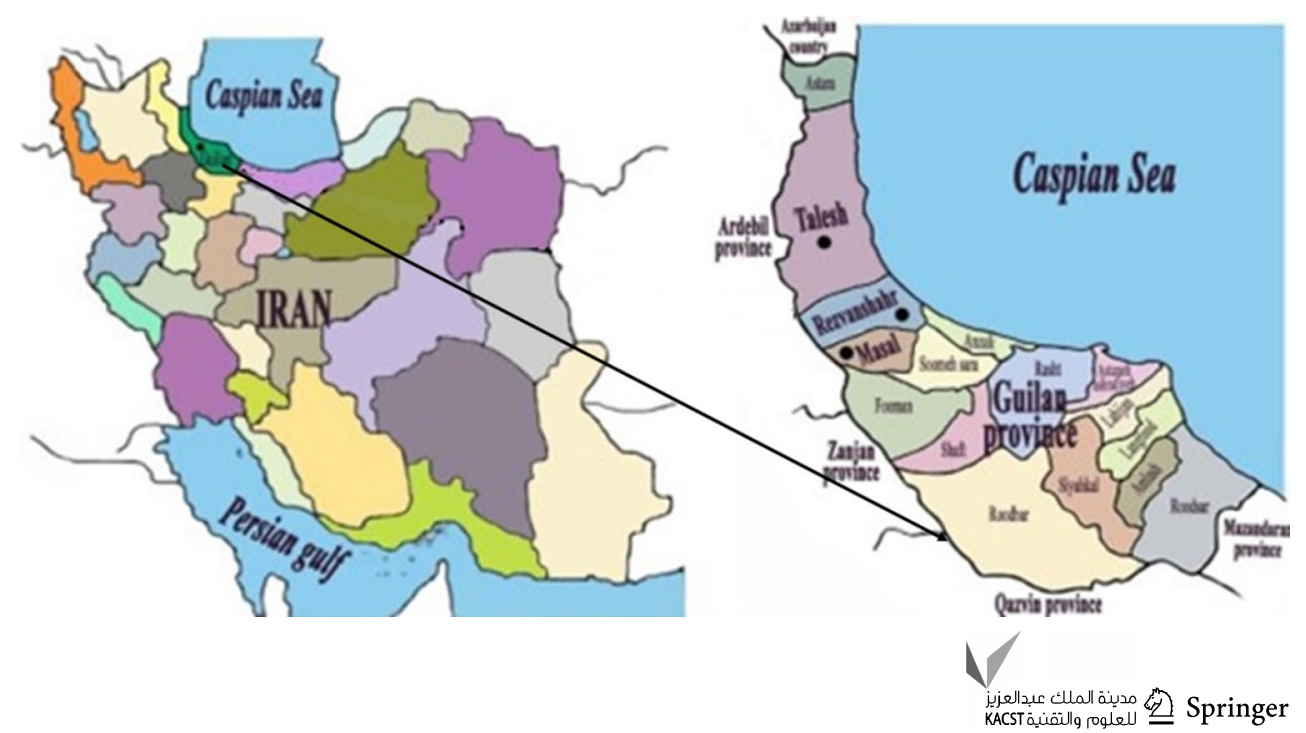


SPSS $_{\mathrm{V} 19}$ software and SmartPLS $\mathrm{V}_{3}$ software were used in descriptive and inferential statistics. For testing hypotheses, structural equation modeling (SEM) and PLS that focus on reagent variance were used.

The research model tested in this study is shown in Fig. 3. According to the UTAUT, facilitating conditions and behavioral intention are hypothesized to be the determinants of use behavior, and performance expectancy, effort expectancy and social influence are hypothesized to be the determinants of behavioral intention in the context of irrigation technology adoption.

The research hypotheses are shown below. All of the constructs and hypotheses in the research model are proposed based on the original UTAUT (Table 1).

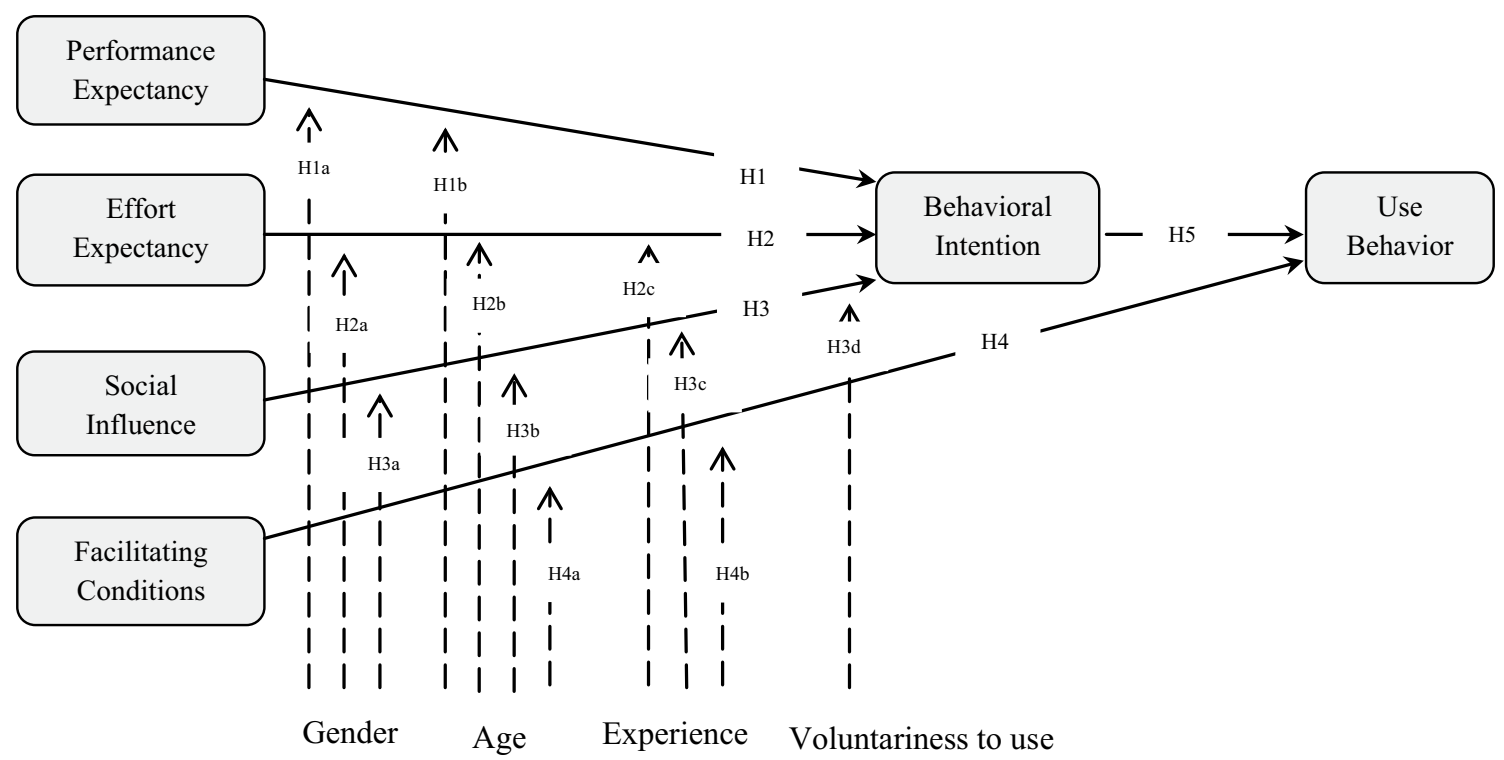

Fig. 3 Research model

Table 1 Hypotheses of research model

\begin{tabular}{ll}
\hline Hypotheses \\
\hline H1 & Performance expectancy has a positive effect on behavioral intention to use irrigation technology \\
H1a & Performance expectancy influences behavioral intention to use irrigation technology more strongly for men than for women \\
H1b & Performance expectancy influences behavioral intention to use irrigation technology more strongly for younger than for older people \\
H2 & Effort expectancy has a positive effect on behavioral intention to use irrigation technology \\
H2a & Effort expectancy influences behavioral intention to use irrigation technology more strongly for women than for men \\
H2b & Effort expectancy influences behavioral intention to use irrigation technology more strongly for older than for younger people \\
H2c & Effort expectancy influences behavioral intention to use irrigation technology more strongly for more experienced than for less experi- \\
H3 & Social influence has a positive effect on behavioral intention to use irrigation technology \\
H3a & Social influence influences behavioral intention to use irrigation technology more strongly for women than for men \\
H3b & Social influence influences behavioral intention to use irrigation technology more strongly for older than for younger people \\
H3c & Social influence influences behavioral intention to use irrigation technology more strongly for more experienced than for less experienced \\
H4 & Feople \\
H4a & Facilitating conditions have a positive influence on irrigation technology use behavior \\
H4b & Facilitating conditions influence irrigation technology use behavior more strongly for more experienced than for less experienced people \\
H4d & Facilitating conditions influence irrigation technology use behavior more strongly for optional users than for forced users \\
H5 & Behavioral intention has a positive influence on irrigation technology use behavior \\
\hline
\end{tabular}




\section{Results}

A significant part of the respondents $(71.4 \%)$ were in the age range of 40-60 years, and most respondents were male (94.8\%). The experience of the respondents ranged from 5 to 40 years. Majority of respondents (46.2\%) had $11-20$ years of experience. Most pressurized irrigation technology users have used it optionally (77.03\%). Moreover, 23.8\% of respondents $(n=50)$ describe themselves as illiterate; $44.3 \%$ of respondents $(n=93)$ had high school education; and $31.9 \%$ of them $(n=67)$ had academic education. Only $38.09 \%$ of respondents have used extension service. Meanwhile, only $29.53 \%$ of respondents have used bank loans (Table 2).

The reliability of factors was approved by principal component analysis (PCA), Cronbach's alpha and Dillon-Goldstein's $\int$ (composite reliability). Due to Cronbach's alpha strict estimate, Dillon-Goldstein's $\int$ was used (Azar et al. 2012). Also, the reliability of measures was approved by outer loadings. Results revealed that outer loadings for EE1 and SI3 were less than 0.7. Based on Bontis et al. (2002),

Table 2 Characteristics of the respondents $(n=210)$

\begin{tabular}{|c|c|c|}
\hline Features & Frequency & Percentage \\
\hline \multicolumn{3}{|l|}{ Gender } \\
\hline Male & 199 & 94.8 \\
\hline Female & 11 & 5.2 \\
\hline \multicolumn{3}{|l|}{ Age (years) } \\
\hline 30 and less & 7 & 3.3 \\
\hline $31-40$ & 39 & 18.6 \\
\hline $40-50$ & 75 & 35.7 \\
\hline $50-60$ & 75 & 35.7 \\
\hline 60 and above & 14 & 6.7 \\
\hline \multicolumn{3}{|c|}{ Experience (years) } \\
\hline 10 and less & 55 & 26.2 \\
\hline $11-20$ & 97 & 46.2 \\
\hline $20-30$ & 52 & 24.8 \\
\hline 30 and above & 6 & 2.9 \\
\hline \multicolumn{3}{|c|}{ Use of pressurized irrigation technology } \\
\hline Yes & 74 & 35.3 \\
\hline No & 136 & 64.7 \\
\hline \multicolumn{3}{|c|}{ Voluntariness to use pressurized irrigation technology } \\
\hline Optional & 57 & 77.03 \\
\hline Mandatory & 17 & 22.97 \\
\hline \multicolumn{3}{|c|}{ Extension service } \\
\hline Yes & 80 & 38.09 \\
\hline No & 130 & 61.91 \\
\hline \multicolumn{3}{|c|}{ Financial service } \\
\hline Yes & 62 & 29.53 \\
\hline No & 148 & 70.47 \\
\hline
\end{tabular}

measures can be saved if average variance extracted (AVE) is more than 0.5 and measures numbers are less than 5 (Table 3).

The validity of factors was approved by average variance extracted (AVE) Fornell and Larcker test. The validity of measures was approved by cross loadings.

AVE for each factor was more than squared correlation of that factor with other reflective factors in the model, so discriminant validity for factors was approved by Fornell and Larcker test (Table 4). Discriminant validity for measures was approved by cross loadings.

The results of UTAUT model showed that there was a significant relationship between "performance expectancy" and "behavioral intention," "social influence" and "behavioral intention," "facilitating condition" and "use behavior of pressurized irrigation technologies." Also, there was a significant relationship between "intention to use" and "use behavior of pressurized irrigation technologies." Moderators (age, gender, experience and voluntariness of use) have shown no evidence of any significant interactions (Table 5). Performance expectancy is the strongest predictor of behavioral intention to use.

Both behavioral intention and facilitating condition were found to have a significant positive effect on pressurized irrigation technologies adoption. The model explained $72 \%$ of the variance in behavioral intention and $47 \%$ of the variance in using pressurized irrigation technologies among olive farmers (Table 6; Fig. 4).

\section{Discussion and conclusion}

Based on the results obtained from olive groves on water supply, most of the owners provide their groves irrigation water from rivers, streams and wells of the seven irrigation sources. This can be due to the availability of streams and rivers, as well as high levels of ground water, high water quality and flow of water. These results indicate that olive farmers have less difficulty in terms of water supply, but more needs to equipment for the production process (technology). Based on the results obtained on the grove capacity, most groves were with a capacity of 1-10 ha. Most olive farmers have a grove of 2 ha. Olive farmers experience ranges from 10 to 20 years with an average of 18 years. Low capacity of grove production is one of the major barriers to technical development in olive groves.

$\mathrm{T}$ test results showed that benefit from loans and banking facilities has a significant effect on the use of irrigation technology on the level of one percent error. This result is consistent with Riahi et al. (2010), Nejadrezaei et al. (2015) and Tiamiyu et al. (2009). Also, the results of $t$ test showed that consultation with extension agents has a significant effect on the use of irrigation technology on the level of one percent

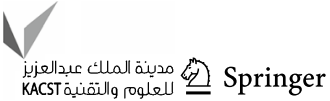


Table 3 Factor loadings, reliability and validity

\begin{tabular}{|c|c|c|c|c|c|c|}
\hline Factor & Measures & Factor loadings & $\mathrm{AVE}^{\mathrm{a}}$ & $\mathrm{CR}^{\mathrm{b}}$ & Cronbach's alpha & $\begin{array}{l}\text { Reliability } \\
\text { and valid- } \\
\text { ity }\end{array}$ \\
\hline \multirow[t]{4}{*}{ Performance expectancy (PE) } & PE1 & 0.897 & \multirow[t]{4}{*}{0.757} & \multirow[t]{4}{*}{0.925} & \multirow[t]{4}{*}{0.893} & \multirow[t]{4}{*}{ Accepted } \\
\hline & PE2 & 0.901 & & & & \\
\hline & PE3 & 0.830 & & & & \\
\hline & PE4 & 0.852 & & & & \\
\hline \multirow[t]{4}{*}{ Effort expectancy (EE) } & EE1 & 0.675 & \multirow[t]{4}{*}{0.609} & \multirow[t]{4}{*}{0.861} & \multirow[t]{4}{*}{0.786} & \multirow[t]{4}{*}{ Accepted } \\
\hline & EE2 & 0.779 & & & & \\
\hline & EE3 & 0.821 & & & & \\
\hline & EE4 & 0.835 & & & & \\
\hline \multirow[t]{3}{*}{ Social influence (SI) } & SI1 & 0.945 & \multirow[t]{3}{*}{0.631} & \multirow[t]{3}{*}{0.817} & \multirow[t]{3}{*}{0.655} & \multirow[t]{3}{*}{ Accepted } \\
\hline & SI2 & 0.942 & & & & \\
\hline & $\mathrm{SI} 3$ & 0.338 & & & & \\
\hline \multirow[t]{4}{*}{ Facilitating condition (FC) } & $\mathrm{FC} 1$ & 0.833 & \multirow[t]{4}{*}{0.692} & \multirow[t]{4}{*}{0.899} & \multirow[t]{4}{*}{0.851} & \multirow[t]{4}{*}{ Accepted } \\
\hline & $\mathrm{FC} 2$ & 0.797 & & & & \\
\hline & FC3 & 0.867 & & & & \\
\hline & FC4 & 0.830 & & & & \\
\hline \multirow[t]{4}{*}{ Behavioral intention (BI) } & BI1 & 0.897 & \multirow[t]{4}{*}{0.743} & \multirow[t]{4}{*}{0.920} & \multirow[t]{4}{*}{0.884} & \multirow[t]{4}{*}{ Accepted } \\
\hline & $\mathrm{BI} 2$ & 0.894 & & & & \\
\hline & $\mathrm{BI} 3$ & 0.885 & & & & \\
\hline & BI4 & 0.822 & & & & \\
\hline
\end{tabular}

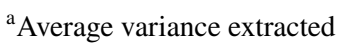

${ }^{\mathrm{b}}$ Composite reliability

Table 4 Fornell and Larcker test

\begin{tabular}{|c|c|c|c|c|c|c|}
\hline Factor & $\mathrm{BI}$ & $\mathrm{EE}$ & FC & $\mathrm{PE}$ & SI & UB \\
\hline Behavioral intention (BI) & $\mathrm{AVE}=0.743$ & & & & & \\
\hline Effort expectancy (EE) & 0.245 & $\mathrm{AVE}=0.609$ & & & & \\
\hline Facilitating condition $(\mathrm{FC})$ & 0.724 & 0.252 & $\mathrm{AVE}=0.692$ & & & \\
\hline Performance expectancy (PE) & 0.702 & 0.241 & 0.643 & $\mathrm{AVE}=0.757$ & & \\
\hline Social influence (SI) & 0.190 & 0.203 & 0.159 & 0.152 & $\mathrm{AVE}=0.631$ & \\
\hline Use behavior (UB) & 0.442 & 0.108 & 0.426 & 0.383 & 0.089 & $\mathrm{AVE}=1.000$ \\
\hline
\end{tabular}

error. Low levels of extension services are likely to be effective in the early stage of technology awareness in the admission process. This result is consistent with Tiamiyu et al. (2009), Adeokun et al. (2006) and Akudugu et al. (2012).

The results of $F$ test showed that type of water supply has a significant effect on the use of irrigation technology on the level of one percent error. This result is consistent with Nejadrezaei et al. (2015). The size of the grove has a significant effect on the use of irrigation technology on the level of one percent error. This result is consistent with Wetengere (2009).

The first hypothesis (H1) was accepted. This means that there is a significant relationship between performance expectancy and behavioral intention to use irrigation technology. Olive groves' managers believe that pressurized irrigation technology is useful. They have accepted it and believe that the use of pressurized irrigation technology helps them to increase their effectiveness. In similar studies, Meng and Cao (2010), Bahramzadeh and Shokati Mogharab (2010), Im et al. (2011), Yu (2012), Wang and Shin (2009), Wu et al. (2011) and Nejadrezaei et al. (2015) have found a positive relationship between performance expectancy and behavioral intention to use technology. The results of this study, like the studies of Wang and Shin (2009) and Nejadrezaei et al. (2015), showed that the performance expectancy is the most powerful in the intention of using technology.

The second hypothesis (H2) was rejected. This means that there is no significant relationship between effort expectancy and behavioral intention to use irrigation technology. 
Table 5 PLS final results with and without moderator variables

\begin{tabular}{|c|c|c|c|c|c|c|}
\hline Path & SD & Path coefficients & $t$ value & $p$ value & $\begin{array}{l}\text { Reliability and } \\
\text { validity }\end{array}$ & Remarks \\
\hline PE BI & 0.047 & 0.761 & 15.378 & 0.001 & $\mathrm{Y}$ & Significant \\
\hline $\mathrm{PE} \rightarrow \mathrm{BI}{ }^{*}$ gender & - & 0.749 & 0.677 & - & $\mathrm{Y}$ & Not significant \\
\hline $\mathrm{PE} \rightarrow \mathrm{BI} *$ age & - & -0.002 & 0.020 & - & $\mathrm{Y}$ & Not significant \\
\hline $\mathrm{EE} \rightarrow \mathrm{BI}$ & 0.039 & 0.074 & 1.757 & - & $\mathrm{Y}$ & Not significant \\
\hline $\mathrm{EE} \rightarrow \mathrm{BI} *$ gender & - & 0.162 & 0.464 & - & $\mathrm{Y}$ & Not significant \\
\hline $\mathrm{EE} \rightarrow \mathrm{BI} *$ Age & - & 0.081 & 1.073 & - & $\mathrm{Y}$ & Not significant \\
\hline $\mathrm{EE} \rightarrow \mathrm{BI} *$ experience & - & -0.042 & 0.712 & - & $\mathrm{N}$ & Not significant \\
\hline $\mathrm{SI} \rightarrow \mathrm{BI}$ & 0.043 & 0.105 & 2.566 & 0.01 & $\mathrm{Y}$ & Significant \\
\hline $\mathrm{SI} \rightarrow \mathrm{BI} *$ gender & - & 0.042 & 0.195 & - & $\mathrm{Y}$ & Not significant \\
\hline $\mathrm{SI} \rightarrow \mathrm{BI} *$ age & - & -0.015 & 0.317 & - & $\mathrm{Y}$ & Not significant \\
\hline $\mathrm{SI} \rightarrow \mathrm{BI} *$ experience & - & -0.024 & 0.551 & - & $\mathrm{Y}$ & Not significant \\
\hline $\mathrm{SI} \rightarrow \mathrm{BI} *$ voluntariness of use & - & -0.040 & 0.941 & - & $\mathrm{Y}$ & Not significant \\
\hline $\mathrm{FC} \rightarrow \mathrm{UB}$ & 0.113 & 0.315 & 2.893 & 0.01 & $\mathrm{Y}$ & Significant \\
\hline $\mathrm{FC} \rightarrow \mathrm{UB} *$ age & - & 0.095 & 1.001 & - & $\mathrm{Y}$ & Not significant \\
\hline $\mathrm{FC} \rightarrow \mathrm{UB} *$ experience & - & -0.046 & 0.614 & - & $\mathrm{N}$ & Not significant \\
\hline $\mathrm{BI} \rightarrow \mathrm{UB}$ & 0.103 & 0.397 & 4.008 & 0.001 & $\mathrm{Y}$ & Significant \\
\hline
\end{tabular}

Table $6 R$ square

\begin{tabular}{ll}
\hline Variables & $R$ square \\
\hline Performance expectancy & - \\
Effort expectancy & - \\
Social influence & - \\
Facilitating conditions & - \\
Behavioral intention & 0.720 \\
Use behavior & 0.470 \\
\hline
\end{tabular}

Pressurize irrigation technology ease of use affects technology usage. The results indicate that olive groves' managers do not accept pressurized irrigation technology ease of use because they believe that the use of pressurized irrigation technology has not been easy. In similar studies, Meng and Cao (2010), Yu (2012), Wu et al. (2011) and Nejadrezaei et al. (2015) have found no relationship between effort expectancy and behavioral intention to use. Despite the rejection of the relationship in this research, Wang and Shin
(2009), Bahramzadeh and Shokati Mogharab (2010) and Im et al. (2011) have found a positive relationship between effort expectancy and behavioral intention to use technology. Bahramzadeh and Shokati Mogharab (2010) concluded that effort expectancy is the most powerful factor in behavioral intention to use information technology in ABFA co. The difference in these findings may be due to differences in cultural contexts.

The third hypothesis (H3) was accepted. This means that there is a significant relationship between social influence and behavioral intention to use irrigation technology. The results suggest that olive groves' managers believe that using or not using technologies is influenced by other individuals and their way of thinking. In similar studies, Meng and Cao (2010), Bahramzadeh and Shokati Mogharab (2010), Im et al. (2011), Yu (2012), Wang and Shin (2009) and Wu et al. (2011) have found a positive relationship between social influence and behavioral intention to use technology. Yu (2012) concluded that social influence is the most powerful factor in behavioral

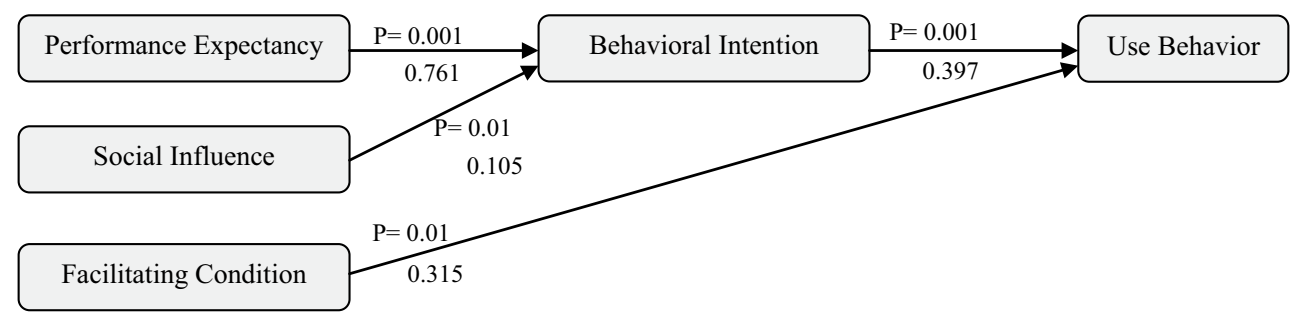

Fig. 4 Measurement model results 
Table 7 Summary of accepted hypotheses

\begin{tabular}{lll}
\hline Hypotheses & & Results \\
\hline H1 & Performance expectancy has a positive effect on behavioral intention to use irrigation technology & Accepted \\
H3 & Social influence has a positive effect on behavioral intention to use irrigation technology & Accepted \\
H4 & Facilitating conditions have a positive influence on irrigation technology use behavior & Accepted \\
H5 & Behavioral intention has a positive influence on irrigation technology use behavior & Accepted \\
\hline
\end{tabular}

intention to use Internet banking. Nejadrezaei et al. (2015) concluded that there is no significant relationship between social influence and behavioral intention.

The fourth hypothesis (H4) was accepted. This means that there is a significant relationship between facilitating condition and irrigation technology use behavior. Facilitating conditions for olive farmers (organizational support, training and application of irrigation technology) is the reason of using pressurized irrigation technology in Roudbar. In similar studies, relationship between facilitating condition and technology use behavior was approved by Wang and Shin (2009), Wu et al. (2011) and Im et al. (2011). Im et al. (2011) concluded that facilitating condition is the most powerful factor in Internet banking and music players use behavior among American and Korean students. Meanwhile, Meng and Cao (2010), Yu (2012), Bahramzadeh and Shokati Mogharab (2010) and Nejadrezaei et al. (2015) concluded that there is no significant relationship between facilitating condition and technology use behavior.

The fifth hypothesis (H5) was accepted. The correlation coefficient between behavioral intention and irrigation technology use behavior represents the direct correlation between them. This means that there is a significant relationship between behavioral intention and pressurized irrigation technology use behavior. The results indicate that olive farms' managers are mentally prepared to apply the pressurized irrigation technologies. In similar studies, relationship between behavior intention and technology use behavior was approved by Meng and Cao (2010), Bahramzadeh and Shokati Mogharab (2010), Im et al. (2011), Yu (2012), Wang and Shin (2009), Wu et al. (2011) and Nejadrezaei et al. (2015). Wang and Shin (2009) concluded that behavioral intention is the most powerful factor in technology use behavior.

Regarding moderator role in the model, none of four moderator variables (gender, age, experience and voluntariness to use) moderate relationships between the main variables (Table 7).

For increasing willingness to adopt pressurized irrigation technology in olive farms, it is suggested that extension courses and training should be held by organizations to increase the level of knowledge and awareness of olive farmers. Also, by providing necessary financial and knowledge resources, olive farmers can be encouraged to use pressurized irrigation system.

Acknowledgements Financial support by Rasht Branch, Islamic Azad University Grant No. 4.5830, is acknowledged.

\section{Compliance with ethical standards}

Conflict of interest No conflict of interest is confirmed.

Open Access This article is distributed under the terms of the Creative Commons Attribution 4.0 International License (http://creativeco mmons.org/licenses/by/4.0/), which permits unrestricted use, distribution, and reproduction in any medium, provided you give appropriate credit to the original author(s) and the source, provide a link to the Creative Commons license, and indicate if changes were made.

\section{References}

Addo H (2014) Using the UTAUT model to analyze students' ICT adoption. Int J Educ Dev Inf Commun Technol 10(3):75-86

Adeokun OA, Adereti FO, Opele AI (2006) Factors influencing adoption of fisheries innovations by artisanal fisherman in coastal areas of Ogun State, Nigeria. J Appl Sci Res 2(11):966-971

Adeoti A (2009) Factors influencing irrigation technology adoption and its impact on household poverty in Ghana. J Agric Rural Dev Trop Subtrop 109(1):51-63

Afrakhteh H, Armand M, Askari Bozayeh F (2014) Analysis of factors affecting adoption and application of sprinkler irrigation by farmers in Famenin County, Iran. Int J Agric Manag Dev 5(2):89-99

Ajzen I (1991) The theory of planned behavior. Organ Behav Hum Decis Process 50(2):179-211

Akudugu MA, Guo E, Dadzie SK (2012) Adoption of modern agriculture production technology by farm households in Ghana: what factors influence their decisions. J Biol Agric Healthc 2(3):1-13

Azar A, Ghollamzadeh R, Ghanavati M (2012) Path-structural modeling in management, 1st edn. Negahedanesh, Tehran

Bahramzadeh MM, Shokati Mogharab S (2010) Cultural approach to IT: compliance evaluation based on UTAUT. In: 8th international conference on management. http://www.civilica.com/Paper -IRIMC08-IRIMC08_084.html. Accessed Sept 2015

Bandura A (1989) Social cognitive theory. In: Vasta R (ed) Annals of child development, vol 6. Six theories of child development. JAI Press, Greenwich, CT, pp 1-60

Bartlett JE, Kotrlik JW, Higgins CC (2001) Organizational research: determining appropriate sample size in survey research. Inf Technol Learn Perform J 19(1):43-50 
Bontis N, Crossan MM, Hulland J (2002) Managing an organizational learning system by aligning stocks and flows. J Manage Stud 39(4):437-469

Celano G, Dichio B, Montanaro G, Nuzzo V, Palese AM, Xiloyannis C (1999) Distribution of drymatter and amount of mineral elements in irrigated and non-irrigated olive trees. Acta Hortic 474:381-384

Compeau D, Higgins C (1995) Computer self-efficacy: development of a measure and initial test. MIS Q 19:189-211

Davis FD (1989) Perceived usefulness, perceived ease of use, and user acceptance of information technology. MIS Quarterly 13(3):319-339

Davis FD, Warshaw PR (1992) Extrinsic and intrinsic motivation to use computers in the workplace. J Appl Soc Psychol 22(14):1111-1132

Fernandez JE, Moreno F (1999) Water use by the olive tree. J Crop Prod 2(2):101-162

Firouzi S, Nikkhah A, Aminpanah H (2018) Resource use efficiency of rice production upon single cropping and ratooning agro-systems in terms of bioethanol feedstock production. Energy 50:694-701

Fishbein M, Ajzen I (1975) Belief, attitude, intention, and behavior: an introduction to theory and research. Reading, Addition-Wesley, MA

Holzapfel EA, Pannunzio A, Lorite I, Silva de Oliveira AS, Farkas I (2009) Design and management of irrigation systems. Chil J Agric Res 69:17-25

Im I, Hong S, Kang MS (2011) An international comparison of technology adoption testing the UTAUT model. J Inf Manag 4:1-8

Kumar R, Singh J (2003) Regional water management modelling for decision support in irrigated agriculture. J Irrig Drain Eng 129:432-439

Laraus J (2004) The problem of sustainable water use in the Mediterranean and research requirements for agriculture. Ann Appl Biol 144:259-272

Meng J, Cao Q (2010) Consumer adoption of enterprises microblog marketing services: an analysis based on UTAUT. http://www. academicpub.org. Accessed Sept 2015

Moore GC, Benbasat I (1991) Development of an instrument to measure the perceptions of adopting an information technology innovation. Info Syst Res 2(3):173-239

Movahedi R, Izadi N, Vahdat Adab R (2017) Investigating factors affecting farmers' adoption of pressurized irrigation tchnology in Asadabad County, Hamedan Province. J Water Res Agric $31(2): 22-33$
Nejadrezaei N, Khara H, Allahyari MS, Sadeghzadeh M, Gharra K (2015) Effective factors on adoption technology among trout fish farms in Guilan Province. Iran Sci Fish J 24(3):107-124

Nikkhah A, Emadi B, Soltanali H, Firouzi S, Rosentrater KA, Allahyari MS (2016) Integration of life cycle assessment and Cobb-Douglas modeling for the environmental assessment of kiwifruit in Iran. J Clean Prod 137:843-849

Riahi R, Zamanpour A, Roosta K, Farhangfar H (2010) Logistics analyzes of the factors affecting the adoption of pistachio crop insurance. J Agric Insur Fund 6(22):109-128

Rogers EM (2003) Diffusion of innovations (5th Ed.). Free Press, New York

Taiwo A, Downe A (2013) The theory of user acceptance and use of technology (UTAUT): a meta-analytic review of empirical findings. J Theor Appl Inf Technol 49(1):48-58

Taylor S, Todd PA (1995) Understanding information technology usage: a test of competing models. Info Syst Res 6:144-176

Thompson R, Higgins C, Howell J (1991) Personal computing toward a conceptual model of utilization. MIS Q 15(1):125-143

Tiamiyu JO, Akintola AO, Rahji MAY (2009) Technology adoption and productivity difference among growers of new rice for Africa in Savanna Zone of Nigeria. Tropicultura 27(4):193-197

Venkatesh V, Morris MG, Davis GB, Davis FD (2003) User acceptance of information technology: toward a unified view. MIS Q 27(3):425-478

Wang YS, Shin YW (2009) Why do people use information kiosks? A validation of the unified theory of acceptance and use technology. Gov Inf J 26:158-165

Wetengere K (2009) Socio-economic factors critical for adoption of fish farming technology: the case of selected villages in eastern Tanzania. Int J Fish Aquac 1(3):028-037

Wu YL, Tao YH, Yang PC (2011) Using UTAUT to explore the behavior of $3 \mathrm{G}$ mobile communication users. http://www.tophqbooks .com/books/185591. Accessed Sept 2015

Yu CS (2012) Factors affecting individuals to adopt mobile banking: empirical evidence from the UTAUT model. J Electron Commer Res 13(2):104-121

Publisher's Note Springer Nature remains neutral with regard to jurisdictional claims in published maps and institutional affiliations. 